\title{
Reverse Logistics in Chongqing Construction Industry
}

\author{
Xiao-Yi YUAN \\ Chongqing Real Estate College, Chongqing, China \\ cn.yuanxiaoyi@gmail.com
}

Keywords: Reverse Logistics, Construction and Demolition Waste, Recycling.

\begin{abstract}
The process of urbanization in Chongqing has increased the generation of construction and demolition wastes, and many of them are not properly disposed, which triggered many environmental problems. With more and more national and regional regulatory means being brought out, construction firm pay more attention on the problem of waste disposal. Based on the research of several construction firms in Chongqing, the aim of this paper is to introduce some solutions on dealing with construction and demolition wastes, including reverse logistics and reverse distribution channel networks.
\end{abstract}

\section{Introduction}

The rapid growth of urbanization process in western China has increased the generation of construction and demolition (C\&D) wastes. For most construction firms, they generally carry out unconnected building projects, situated in different locations, involving numerous suppliers, and using intensive unskilled labors. And the lack of municipal policies have aggravated public problems related to the collection, transport and disposal of $C \& D$ wastes, with the illegal disposal of $C \& D$ waste being frequently observed in places such as streets, pavements, wastelands, hillsides and river beds. Only a few construction firms in Chongqing have installed mature $C \& D$ waste recycling/processing channels, while many other firms do not dispose C\&D waste in waste dumps or landfill site, due to high-running-cost and low-penalty-cost. With more strict environmental protection measures brought out by national and regional authorities, more and more firms are considering reverse logistics as a strategic activity not only because it can reduce the penalty cost, but also it can create value.

Based on conducting in-depth investigation and research in six construction firms in Chongqing, two of which have almost completed $C \& D$ waste reverse logistics, the objective of this paper is to introduce the concepts of reverse logistics and reverse distribution channel networks for C\&D waste management in Chongqing.

\section{Literature Research}

\section{Supply Chains}

According to [1]-[2], direct supply chains are composed of the various stages in which the produced goods are sold until they reach the final consumer, whether they are an individual or a company. The physical distribution of goods is the activity that involves the movement and making available of these products to the final consumer.

Reverse supply chains can be defined as the stages and means through which the goods produced, or parts of them, return to the productive cycle reacquiring value in secondary markets by reuse or the recycling of their constituent materials. If the return of these materials to the business cycle is not economically viable, there are options for final disposal, such as landfills and waste dumps.

\section{Reverse Logistics}

Traditional logistics basically involve the location of the necessary facilities, transport, stock, the movement of material, the level of integration of logistics activities and a suitable information system to make the various flows of materials and merchandise efficient.

Reverse logistics can be defined as how the area of business logistics plans, operates and controls the flow of logistics information corresponding to the return of post-sale and post-consumption goods to the 
productive cycle through reverse distribution channels, adding value of various types to them, such as economic, ecological, legal, logistical, corporate image, etc.

It should be noted that in the most economically developed countries have greater experience with reverse channels in comparison with developing countries. And a more mature and widespread perception of environmental problems exists in these developed countries.

\section{Reverse Logistics and Integrated C\&D Waste Management}

Fig. 1 shows the productive chain of the construction firms, where the direct distribution channels are illustrated, beginning with the firms that extract the raw materials, which may or may not be processed by the companies that manufacture construction materials, and reaching construction activities.

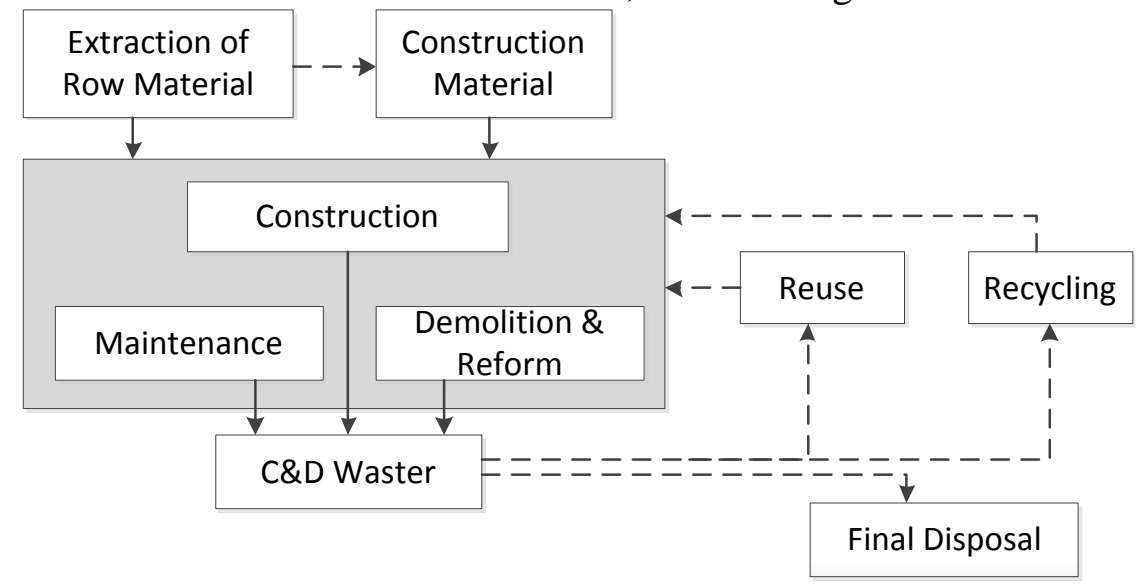

Fig. 1. Direct and indirect supply chains in construction firms

Starting from the general concept of reverse logistics and focusing on the question of C\&D waste within the Chongqing construction industry, the following characteristics can be listed:

- Within the direct distribution channels, the flows of raw materials that involve large quantities of sand, gravel, cement, ceramic parts, steel and other materials;

- Production areas are generally located remotely from construction sites, as a result of which the costs of transporting material significantly influence the final construction costs;

- In reverse distribution channels, the largest secondary flows of materials are the inert mineral wastes related to plaster, concrete, bricks and ceramic screens;

- It has been observed that construction reverse distribution channels have attracted little attention from entrepreneurs, and the possibilities of using waste as secondary material are relatively unexploited;

- The majority of C\&D waste collected by public authorities in Chongqing is currently disposed of in waste dumps or landfill sites. The local authorities haven't had efficient solutions for either small or large $\mathrm{C} \& \mathrm{D}$ waste generators;

- To reduce transport costs, C\&D waste recycling centers need to be located near construction sites, which are both the source of $C \& D$ waste materials and the consumer market for processed materials;

- On the other hand, the most central areas are generally close to densely populated regions, which can hinder the construction of recycling facilities;

- The companies that operate the landfills are generally paid per ton received and therefore the more C\&D waste they receive, the greater benefits they will receive. And the companies running landfills always have local government backgrounds;

- The C\&D waste recycling process predominantly takes place in down cycling, where the recycled product is used as a material with inferior characteristics in comparison with its previous use.

\section{C\&D Waste Recycling Centers}

By learning from the mature construction firms with recycling centers, all these firms have a greater size, and have more construction projects than other firms without recycling centers. Moreover, these firms draw much more regulatory attention than others. And smaller firms have little enthusiasm on 
installing a self-running recycling center rather than taking advantage of public or third party recycling centers.

In order to properly operate recycling centers with feasibility and viability, the following conclusions are drawn:

- The feasibility of these centers for public authorities also depends on continuity and a volume of production close to planned capacity;

- The implementation and operation of private $C \& D$ waste recycling centers based on private investment and initiative were not feasible, due to reduced return on investments;

- Since the use of recycled raw materials is still not widespread in Chongqing, it is probable that investments in large-scale recycling centers will have a higher risk of failure than those in small and mid-sized recycling centers.

So it is clear that the municipal managers should install more public recycling centers rather than attracting private investment.

\section{Reverse Distribution Channel Networks}

By learning from the cases of Chongqing construction firms, it is clear that most small and midsize construction firms haven't created any value from $C \& D$ waste disposal, and all of them are willing to take part in the reverse $C \& D$ waste network, which is operated by the government. In order to make the reverse distribution channels feasible, and optimize the reuse and recycling flows and activities, following aspects should be taken into account.

- Definition of the objectives of the reverse network;

- Setting of the integration level and the type of reverse network;

- C\&D waste characteristics and the definition of the final market for the processed product;

- Location of consolidation, dismantling and remanufacturing centers;

- Measurement and information systems for reverse channel operations.

\section{Definition of Objectives of the Reverse Network}

The planning of the reverse C\&D waste network can be motivated by economic, ecological and/or legal aspects. The economic aspects include the reduction of the costs of the collection and transport of illegal waste disposal and the reduction of construction costs, through savings in the acquisition of primary raw materials and in the transport and disposal of C\&D waste. The ecological aspects are mainly composed of the reduction of the environmental impacts of the extraction, transport and processing of natural resources and the extension of the working life of landfill sites. For legal aspects, the most important is upcoming environment regulatory.

\section{Establishing the Level of Integration and Type of Reverse Network}

The following aspects have to be taken into account for decisions about the level of integration and the type of reverse network:

- Current state of the organizations relating to C\&D waste: implementation, or not, of actions for minimizing and recycling these wastes and availability of organizations that recycle the rentable C\&D waste fractions;

- Level of technology used: the recycling centers can use simple or complex technologies;

- Transport operations: number of organizations involved and types of vehicles.

New network components need to be incorporated, while managers of public reverse network can survey potential markets, making contacts and setting up partnerships with neighboring districts, with private companies including transporters, recycling cooperatives, etc.

\section{C\&D Waste Characteristics and the Final Market of Recycled Products}

In analyzing the use of the recycled $C \& D$ waste, it should be recognized that, in general, the quality of these materials is heterogeneous and inferior to that of conventional raw materials. For successful C\&D waste recycling, the homogeneity of the composition and purity of materials must be guaranteed. the recycled materials do not have homogeneous physical or chemical characteristics, which hinders their use 
in concrete structures. As a consequence, the recycling of $C \& D$ waste materials is generally limited to the areas like paving works, drainage works, and hill or river side stabilization, and so on.

Incentives for the use of processed $C \& D$ waste can also be put into practice through, for example, the reduction of taxes and the provision of loans with lower interest rates than practiced in the market for the processing and sale of recycled materials, carrying out building works with recycled materials, and the construction of private recycling centers. Therefore, to attract and maintain clients, the prices of recycled materials need to be lower than those of conventional raw materials.

\section{Location of C\&D Waste Reception and Processing Centers}

As part of a C\&D waste reverse distribution network, enough spaces should be available for the delivery of $C \& D$ waste from big and small producers. Frequently areas used for illegal disposal are located within or near areas under the responsibility of public authorities. A strategy for the creation of $\mathrm{C} \& \mathrm{D}$ waste areas is to make use of some of the locations already used for illegal disposal. Therefore, a network containing smaller sites can be set up for the smaller C\&D waste generators. The material received can be transported to larger areas with a recycling center or an inert landfill.

\section{Measurement and Information Systems for Reverse Channel Operations}

A steady and viable operation of reverse channel needs control devices and structures. Information systems can be very helpful to measure its results, as well as to prevent economic risks, detect poor processed materials quality and overcome delays in the network.

\section{Summary}

This paper focused on the characteristics and problems of C\&D waste disposal in Chongqing, and the concepts of reverse logistics and reverse distribution channel networks for C\&D waste management in Chongqing were also introduced. By in-depth investigation of several construction firms and local policies, this paper listed some aspects that need to be taken into account, when planning a post-consumption reverse network for $\mathrm{C} \& \mathrm{D}$ waste, such as definition of the reverse network, establishment of the level of integration and type of reverse network, and so on.

These actions will support public authorities and private initiative in decisions about the efficiency and economical feasibility of reverse logistics in $C \& D$ waste in Chongqing and in other cities especially those in western China.

\section{References}

[1] Sakis J, Meade LM, Talluri S., E-logistics and the natural environment, Supply Chain Management, 2004, 9(3/4), pp. 303-312.

[2] Mollenkopf DA, Closs D., The hidden value in reverse logistics, Supply Chain Management Review, 2005, 9(5), pp34-43.

[3] Lifset RJ., Take it back: Extended producer responsibility as a form of incentive based environmental policy, Journal of Resource Management and Technology, 1993, 21(4), pp163-175.

[4] Klausner M, Hendrickson CT., Reverse-Logistics strategy for product take-back, Interfaces, 2000, 30(3), pp156-165.

[5] Kumar S, Putnam V., Cradle to cradle: Reverse logistics and opportunities across three industry sectors, International Journal of Production Economics, 2008, pp305-315.

[6] Brito M., Dekker R., A framework for reverse logistics, Berlin, Springer, 2004, pp3-27.

[7] Haas DA, Murphy FH, Lancioni RA, Managing reverse logistics channels with data envelopment analysis, Transportation Journal, 2003, 42(3), pp59-69.

[8] Yu MC, Wu PS, A simulation study of the factors influencing the design of a waste collection channel in Taiwan, International Journal of Logistics, 2010, 13(4), pp257-271. 